should not be considered in isolation but in the wider context of all methods of learning and of teaching. Almost invariably the appropriate use of several methods in combination will produce the best results.

While film and television can be expressions of art in their own right, the primary usefulness will probably be as aids in communication. The selection of the most effective methods of communication presupposes a clear understanding of the end product, what the student is supposed to be able to do, and how he is expected to think and react at the end of his course of studies. An appreciation of the teaching situation and the context in which learning is to take place will be just as important. Furthermore the producer of audio visual aids should base his planning on a clear definition of objectives, on existing knowledge of the proposed audience, and on the purpose of the contents. Finally, students should be given an opportunity to learn how to learn from visual information. Visual literacy, a concept cited by Sir Arthur Elton, is essential for the effective construction, use and acceptance of information. in visual terms by producers, teachers and students respectively. The literature on the effective construction and use of audio visual teaching devices, both for mass instruction and for individual learning, as well as the literature on methods of testing, is considerable and should be made more widely available. It is, therefore, a pleasure to learn that Lord Robbins will be concerned with a new journal on the technology of education, New Education, which is to commence publication in November of this year.

C. E. Engel

\title{
OXFORD CHROMOSOME CONFERENCE
}

A $\mathrm{N}$ international conference on chromosomes, attended by more than a hundred delegates from twenty countries, was held at Magdalen College and the Botany School, University of Oxford, during July 28-31. The deliberations of the conference were of five kinds: dissertations, demonstrations, business meetings, social functions, and extra-mural informal gatherings.

The proceedings began with an address of welcome by Prof. C. D. Darlington in which he recalled for the conference the content of Weismann's classic paper published in Nature $(36,607 ; 1887)$. This he saw as still a charter for those who examine chromosomes.

Thirty other papers were delivered in four sessions. The first, on plants, included a report by Prof. A. Müntzing (Sweden) on accessory $(B)$ chromosomes in Poa and Secale. The latter was also the subject of an investigation by Dr. J. Sybenga (Netherlands) on the possible role of interchanges in determining selective pairing in polysomies. Proferential autosyndesis was not observed, indicating that interstitial changes in homology have no detectable effect on pairing which is localized near the ends. The control of pairing was considered also by Dr. R. Riley (Great Britain), who described work on wheat undertaken jointly with Dr. E. R. Scars (U.S.A.). It revealed a genetic condition which determined asynapsis but only under certain temperature conditions. Other polyploids were the subject of papers by C. J. Marchant (Great Britain) and Prof. J. K. Morton (Sierra Leone). A different aspect of chromosome mechanics, diplotene repulsion, was discussed by Dr. K. Pusa (Finland), who concluded that such a force exists. The chairman of this session was Dr. E. R. Sears and it also contained a paper by Mrs. E. R. Sansome (Nigeria), who presented evidence in favour of the diploid condition of the vegetative phase in the Oömycetes.

The second session was concerned with the structure of the nucleus and with chromosome abnormalities induced by mutagens. Prof. Müntzing acted as the chairman of this session, which included papers by Dr. H. Ris (U.S.A.) and L. F. La Cour (Great Britain), who considered chromosome organization as revealed by the electron microscope and nucleolar structure respectively. There were accounts also by Drs. H-G. Keyl (Western Germany) and B. A. Kihlman (Sweden), who discussed various aspects of DNA synthesis. Papers by Dr. R. C. von Borstel (U.S.A.) and Dr. G. R. Lane (Great Britain) reported investigations on X-ray chromosome breakage while Mr. C. J. Grant (France) discussed the delay in mitosis caused by chemical mutagens. This session included a report by Prof. G. Östergren (Sweden) on the effects on chromosome behaviour of induced point mutations, and he gave a demonstration on the same subject. Of special importance were his observations of chromosomes which entered pollen grain mitosis although they had not divided into chromatids.

Insects and mammals were the subject of the third session, which was chaired by Prof. H. Bauer (Western Germany). It began with a beautiful film of meiosis in Pales by Dr. R. Dietz (Western Germany), who also exhibited three other films at a supernumerary session held on the last day of the conference. These showed that the spindle could function in a normal way even in the absence of centrioles and they threw considerable light on the mechanical behaviour of the hereditary sex univalents of this genus. Other aspects of chromosome movement and their control were described by Dr. I. GeyerDuszýnska (Poland), while the effects of $\alpha$-heterochromatin on crossing-over were considered by Dr. B. E. Wolf (Western Germany). Gene action in Drosophila was the subject of two papers, one by Dr. O. Hess (Western Germany) and the other by Dr. H. D. Berendes (The Netherlands). Chromosome polymorphism in black-flies was considered from the taxonomic point of view by Dr. R. W. Dunbar (Great Britain), who also gave a demonstration, while intra-specific chromosome variation of the Robertsonian type was discussed by Dr. C. E. Ford (Great Britain) and Dr. J. Wahrman (Israel).

Prof. E. Battaglia (Italy) was the chairman of the final session which contained papers dealing with mammals and the recent, far-reaching, discoveries in man. Putative Robertsonian-type variation in humans was described by Dr. J. L. Hamerton (Great Britain), but there was a suggestion that the condition was better regarded as a monosomic one following unequal interchange between acrocentric chromosomes. Dr. M. Fraccaro (Italy) considered the occurrence of iso-chromosomes and deficiencies in the long arm of the X-chromosome in the same species. Attempts to identify the chromosomes of man individually by different methods were discussed by Dr. D. T. Hughes (Great Britain) and by Dr. C. H. Ockey (Great Britain), who supported his paper with a demonstration. Miss U. Mittwoch (Great Britain) reviewed the problem of the Barr-bodies in human females. This session also contained a very interesting account by Dr. S. Ohno (U.S.A.), who described a hitherto unique condition in mammals, namely, an $X O$ soma as the normal state in females of the creeping vole. It is associated with mechanisms leading to the formation of only $X$. carrying eggs and $Y$-or $O$-containing sperm.

The thirty demonstrations included thirteen by members of the host department. They covered a wide range of organisms from microbes to man and a variety of techniques including experimental breeding, autoradiography and electron microscopy. Giant models of meiosis made at the Botany School were exhibited. The spiral structure of chromosomes was demonstrated on closed-circuit 
television by Mr. Canio Vosa (Italy), now of the Botany School, Oxford, and visits to the Genetic Garden of this School were conducted by Prof. Darlington and Mr. Kenneth Burras, the superintendent of the Botanic Garden. This garden contains a collection of variegated plants, chimæras and chromosomally interesting plants used principally for teaching purposes.

These activities, the demonstrations and the papers, served the immediate purpose of the conference which was the exchange of information and ideas. Chromosome investigations have had a tremendous impact on all branches of biology, especially in recent years, and they have established connexions with medicine, agriculture, sociology (anthropology) and the physical scionces. But the extension and expansion of this technique have led to the unforeseen dispersion of chromosome workers themselves and reduced communication between them. Enquiries, beginning at Oxford, had suggested that the need for greater contact could best be fulfilled by regular meetings organized by an international body. With this in view, the chairmen of the four sessions were asked to function as a steering committee and they gave their recommendations at the business meetings.

It was decided that they, by co-option, should increase their number to nine with Dr. K. R. Lewis (Great Britain) as secretary and that this body should serve as an international committee responsible for the second conference of this kind which will be held in Oxford in 1966. At that conference the members of the original steering committee should be replaced by members elected by the conference. Such elected members would then be responsible for the organization of later international conferences every two years. The committee would, by rules or example, indicate the form of future conferences and suggest other activities by which chromosome investigations could be advanced.

The spirit of this first conference indicated a vigorous future for this new venture and anyone interested in it is asked to communicate with me (Botany School, Oxford). The full proceedings of the conference will be published as a supplement to Heredity.

K. R. LEwIS

\title{
SPECTRAL EVIDENCE ON THE ORIGIN OF TYPE I SOLAR RADIO STORMS AND THE CORONAL MAGNETIC FIELD
}

\author{
By J. P. WILD \\ C.S.I.R.O. Radiophysics Laboratory, Sydney, Australia \\ AND \\ A. TLAMICHA \\ Astronomical Institute, Czeskoslovakian Academy of Science, Ondřejov
}

\begin{abstract}
$\mathrm{T}$ HE dynamic spectrum of metre-wave radiation emitted by the Sun during type I storms ${ }^{1,2}$ consists of a conglomeration of storm bursts which are scattered in the time-frequency plane over periods of hours or days and within frequency bands of tens or hundreds of megacycles per second. Owing to the complexity and lack of systematic features in the macroscopic disposition of these bursts, spectrographic investigations have yielded no real clues about the physical nature of the storms as a whole. The purpose of this article is to direct attention to a particular class of systematic macroscopic feature which we have found to be repeatedly evident on the spectral records taken at Dapto, New South Wales, during the last solar cycle. The feature in question is the occurrence of bursts grouped together in tens or hundreds to form narrow-band 'chains' with durations of the order of $1 \mathrm{~min}$ or several min and band-widths of the order of $10 \mathrm{Mc} / \mathrm{s}$. An isolated example of this phenomenon was briefly reported some years ago ${ }^{3}$.

The characteristics of the type I burst-chains are illustrated by the examples given in Figs. 1 and 2 and the left-hand columns of Table 1 ; many more examples can be found in the records and indeed it is our subject.
\end{abstract}

ive impression that the majority of type I radiation may be resolved into chains. The chains may apparently occur in any part of the metre-wave spectrum (30-300 $\mathrm{Mc} / \mathrm{s}$ ) and may drift systematically in frequency at a rate given by $\frac{1}{f}\left|\frac{\mathrm{d} f}{\mathrm{~d} t}\right| \leq 0 \cdot 1$ per $\mathrm{min}$, the average rate being about half that for type II bursts. Although instances have been found in which the drift is positive (that is, from low tc high frequency), the predominant drift is negative as in type II bursts. The chains may occur insignificantly among other complex storm activity, but sometimes dominate the record for periods of up to $1 \mathrm{~h}$ in which a sequence of chains with negative drift follow one another (Fig. 1b). Measurements using the Dapto swept-frequency interferometer have shown that variations in position on the Sun's disk of several minutes of are may accompany the drift in frequency.

It is common, as in the lower record of Fig. 2, to find a pair of chains running roughly (but not exactly) parallel to one another at different frequencies, providing an example of the split-band phenomenon described by Elgaroy $^{2}$. It is not clear whether this circumstance is always due to two independent sources simultaneously

Table 1. Observed and Derived Characteristics of Chains of TYPe I Bursts

\begin{tabular}{|c|c|c|c|c|c|c|}
\hline Date & ర.T. & $\begin{array}{c}\text { Drift in frequency } \\
(\mathrm{Mc} / \mathrm{s})\end{array}$ & $\underset{\text { (min) }}{\text { Duration }}$ & $\begin{array}{l}\text { Movement in height } \\
\left(10^{5} \mathrm{~km}\right)\end{array}$ & $\begin{array}{l}\text { Upward } \\
\text { velocity } \\
(\mathrm{km} / \mathrm{sec})\end{array}$ & $\underset{\text { (gauss) }}{H}$ \\
\hline $\begin{array}{l}\text { April 27, } 1953 \\
\text { August 12, } 1957 \\
\text { March 29, } 1960\end{array}$ & $\begin{array}{l}0018 \\
0038 \\
0045 \\
0223 \\
0229 \\
0239 \\
0449 \\
0458 \\
0512 \\
0514 \\
0602 \\
0610 \\
2345 \\
2352\end{array}$ & $\begin{aligned} & 210 \rightarrow 185 \\
& 230 \rightarrow 180 \\
& 178 \rightarrow 161 \\
& 56 \rightarrow 48 \\
& 50 \rightarrow 44 \\
& 55 \cdot 5 \rightarrow 48 \\
& 63 \rightarrow 58 \\
& 58 \rightarrow 51 \\
& 48 \rightarrow 44 \\
& 61 \cdot 5 \rightarrow 60 \\
& 47 \cdot 5 \rightarrow 45 \cdot 5 \\
& 53 \rightarrow 51 \cdot 5 \\
& 58 \rightarrow 52 \\
& 48 \rightarrow 42 \\
& 56 \rightarrow 44\end{aligned}$ & $\begin{array}{l}1 \cdot 7 \\
4 \cdot 8 \\
2 \cdot 7 \\
4 \cdot 2 \\
3 \cdot 4 \\
4 \cdot 1 \\
1 \cdot 8 \\
2 \cdot 0 \\
5 \cdot 5 \\
2 \cdot 1 \\
0 \cdot 8 \\
0 \cdot 4 \\
1 \cdot 9 \\
2 \cdot 1 \\
2 \cdot 0\end{array}$ & $\begin{array}{l}0 \cdot 9 \rightarrow 1 \cdot 15 \\
0 \cdot 7 \rightarrow 1 \cdot 2 \\
1 \cdot 2 \rightarrow 1 \cdot 4 \\
4 \cdot 3 \rightarrow 4 \cdot 9 \\
4 \cdot 75 \rightarrow 5 \cdot 3 \\
4 \cdot 4 \rightarrow 4 \cdot 9 \\
3 \cdot 9 \rightarrow 4 \cdot 2 \\
4 \cdot 2 \rightarrow 4 \cdot 7 \\
4 \cdot 9 \rightarrow 5 \cdot 3 \\
4 \cdot 0 \rightarrow 4 \cdot 1 \\
5 \cdot 0 \rightarrow 5 \cdot 15 \\
4 \cdot 5 \rightarrow 4 \cdot 65 \\
4 \cdot 2 \rightarrow 4 \cdot 6 \\
4 \cdot 9 \rightarrow 5 \cdot 5 \\
4 \cdot 3 \rightarrow 5 \cdot 3\end{array}$ & $\begin{array}{l}250 \\
160 \\
120 \\
240 \\
260 \\
260 \\
270 \\
410 \\
110 \\
65 \\
380 \\
500 \\
360 \\
460 \\
800\end{array}$ & $\begin{array}{l}2.5 \\
1 \cdot 6 \\
1 \cdot 0 \\
0 \cdot 6 \\
0 \cdot 6 \\
0 \cdot 7 \\
0 \cdot 8 \\
1 \cdot 1 \\
0 \cdot 25 \\
0 \cdot 2 \\
0 \cdot 9 \\
1 \cdot 3 \\
1 \cdot 0 \\
1 \cdot 0 \\
2 \cdot 0\end{array}$ \\
\hline
\end{tabular}

The heights and velocities are derived assuming the radiation to originate at the plasma levels determined from Newkirk's model of the solar atmosphere above an active region. The column $H$ gives the radial component of the magnetic field derived from the assumption that the velocity is 